\title{
Processo de Inertização do Rejeito de Perfuração de Petróleo Através do Processo de Flotação por Ar Induzido
}

\author{
Beatriz I. O. Vieira, Dannielle J. Silva, Hermano G. Fernandes \\ \& Osvaldo Chiavone-Filho
}

Durante a extração do petróleo ocorre a produção de uma corrente aquosa denominada água de produção de petróleo. Este efluente contém compostos orgânicos e inorgânicos de alta periculosidade, e seu destino tem sido um desafio para a indústria petrolífera. Dessa forma, esta pesquisa propõe uma alternativa para a inertização desses compostos através do processo de Flotação por Ar Induzido (FAI), esta operação unitária apresenta simplicidade, alta eficiência na remoção de contaminantes, capacidade para médias e altas vazões, baixo custo operacional e tempo de residência curto, o que implica em menores espaços e economia na construção. Para avaliar este método, foram analisados os teores de carbono orgânico (TOC) e inorgânico (IC) para a água produzida e industrial, de modo a observar a quantidade de contaminante ao longo do processo.

Palavras Chave: água produzida; inertização; flotação.

Inertization process of the oil drilling waste through the Flotation by Induced Air process During the oil extraction occurs the production of an watery current named water produced. This effluent contains highly dangerous organic and inorganic compounds, and its destiny has been a challenge to the oil and gas industry. In this way, this research suggests an alternative to the inertization of these compounds through the Flotation by Induced Air (FIA) process. The device shows simplicity, high efficiency of the removal of contaminants, capacity for medium and high flows, low operational cost and short residence length, which implies in lower spaces and the economy in construction. To evaluate this method, were analyzed the organic and inorganic carbon contents to the industrial and produced water, with the aim to observe the quantity of contaminants during the process.

Keywords: produced water; inertization; flotation. 


\section{Introdução}

É necessária a evolução e inovação na cadeia produtiva do petróleo, que tem se tornado muito importante na matriz energética brasileira e mundial. Diante disso, novas tecnologias são necessárias para manutenção da sua sustentabilidade. Durante a extração do petróleo ocorre a produção de uma corrente aquosa denominada água de produção de petróleo. Este efluente contém, geralmente, alta salinidade, óleo, diversos compostos orgânicos como benzeno, tolueno, etilbenzeno e xileno (BTEX), naftaleno, fenantreno, dibenzotiofeno (NFD), hidrocarbonetos poliaromáticos (HPA), fenóis, gases e metais pesados (Neff, 2002).

O principal resíduo gerado na etapa de perfuração dos poços de petróleo são os denominados cascalhos de perfuração, misturas de pequenos fragmentos de rochas advindos dos fluidos usados na perfuração, sejam eles os fluidos do próprio solo ou mesmo o utilizado para resfriar e lubrificar a broca. Este cascalho é causador de potenciais impactos ao solo e água subterrânea e são classificados como resíduos sólidos devido sua potencial periculosidade, podem adquirir valor comercial se tratados de forma adequada, ao serem utilizados como novas matérias-primas ou novos insumos após inertização.

A flotação é um dos processos de separação extensivamente empregado para recuperação do óleo presente nas fases dispersa e emulsionada de efluentes oleosos, e este método é utilizado nesta pesquisa visando otimizar a corrente líquida recirculada proveniente de um processo de inertização constituído de equipamentos que combinam diferentes processos de separação granulométrica dos sedimentos por peneiramento, com funções de redução das cargas das contaminações e reclassificação do cascalho de perfuração, por conter hidrocarbonetos e sais solúveis.

No método da flotação, partículas hidrofóbicas são seletivamente adsorvidas na superfície da bolha de gás, neste caso o ar, e arrastadas até a superfície onde são concentradas e assim removidas juntamente com a espuma. Esta operação unitária apresenta simplicidade, alta eficiência na remoção de contaminantes, capacidade para médias e altas vazões, baixo custo operacional e tempo de residência curto, o que implica em menores espaços e economia na construção (Rubio et al., 2002).

A probabilidade de uma partícula alcançar a superfície depende do sucesso de três etapas: colisão (PC), adesão (PA) e transporte (PT) (Yoon, 2000), e pode ser representada pela probabilidade de flotação (PF) de acordo com a equação 1 :

$$
\mathrm{PF}=\mathrm{PC} * \mathrm{PA} * \mathrm{PT}
$$

O termo de probabilidade de colisão refere-se a colisão entre a partícula e a bolha de ar. A probabilidade desta etapa é proporcional a razão entre os diâmetros da partícula (Dp) e da bolha de ar $(\mathrm{Db})$, conforme a equação 2 :

$$
\operatorname{Pc} \alpha(\mathrm{Dp} / \mathrm{Db}) 2
$$

Após a colisão bolha-partícula, deverá ocorrer a formação de um agregado, o qual será coletado e analisado.

O objetivo geral desse trabalho é o desenvolvimento de técnica alternativa para tratamento e inertização do cascalho de perfuração de poço, bem como outros sedimentos impactados como solo oriundo de vazamentos.

\section{Metodologia}

Neste trabalho foi utilizado o método da Flotação por Ar Induzido (FAI) para a separação dos compostos orgânicos de alta periculosidade. Através de uma coluna de acrílico com fluxo de ar ascendente e corrente de efluente descendente, foi possível o contato entre bolha-partícula. Como a corrente de ar é ascendente, a amostra é coletada na parte superior da coluna e segue para análise de teor de carbono orgânico (TOC) e teor de carbono inorgânico (IC). Além disso, são verificados multiparâmetros físico-químicos do efluente antes e depois do processo.

Foram utilizados dois tipos de efluentes reais: água produzida e água industrial, ambas com tratamento granulométrico prévio. Além disso, para determinar possíveis traços de óleo na linha de ar provenientes do compressor, foram feitos testes também com água destilada. 


\section{Resultados e Discussão}

Foram analisados os teores de carbono orgânico e inorgânico das amostras coletadas no topo e na base da coluna de flotação, em um intervalo de tempo de 5 minutos entre cada coleta. Estes resultados podem ser vistos nas Figuras 1 a 6, sendo o teor de carbono orgânico representado pelas linhas hachuradas na horizontal, e o teor de carbono inorgânico com linhas hachuradas na diagonal. Este último, possivelmente oriundo de carbonatos dissolvidos e sólidos totais vindos do processo de perfuração de poços de petróleo (formação).

A Figura 1 mostra o valor de TOC e IC da amostra de água industrial residual, a qual foi coletada assim que o processo teve início (T0).

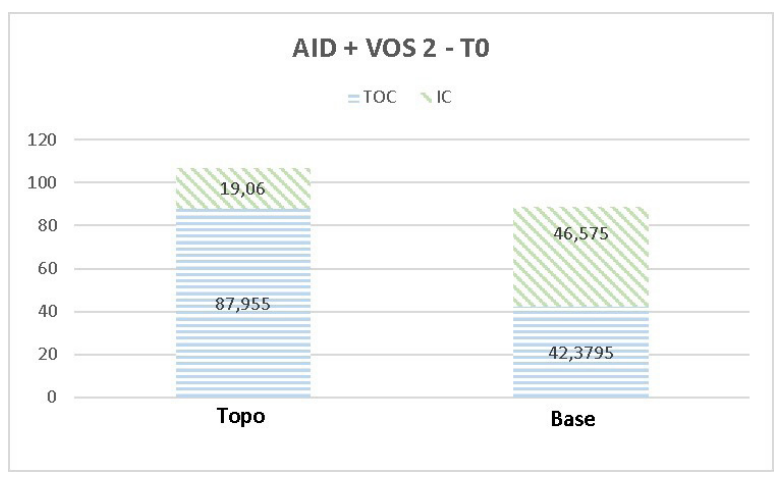

Figura 1. Comparação de TOC e IC entre topo e base de amostra de água industrial (AID) em tempo inicial (T0).

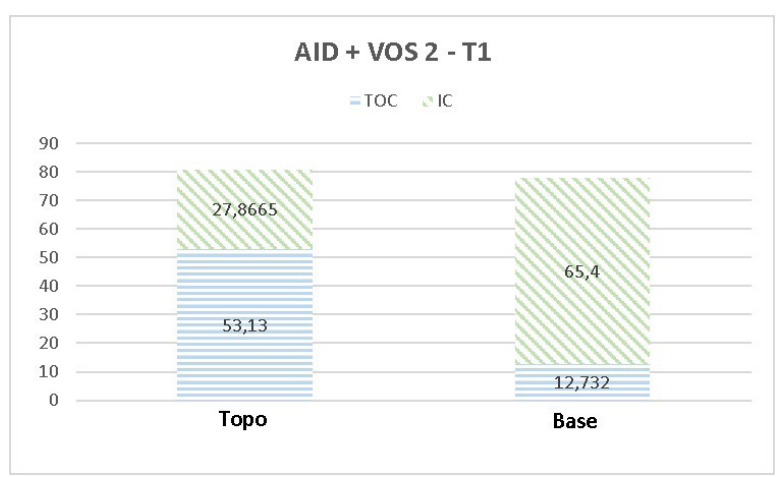

Figura 2. Comparação de TOC e IC entre topo e base de amostra de água industrial em tempo intermediário (T1).
Comparando as Figuras 1 e 2, pode-se perceber a evolução da quantidade de carbono inorgânico no topo e na base. Com relação ao carbono orgânico, observa-se o decrescimento em ambas as coletas. Isso mostra que o processo se torna menos efetivo com o tempo, pois inicialmente há uma maior disponibilidade de orgânicos, facilitando o seu arraste.

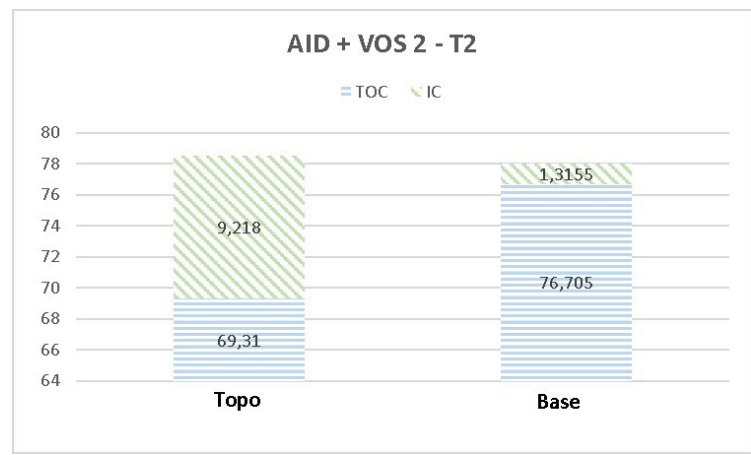

Figura 3. Comparação de TOC e IC entre topo e base de amostra de água industrial em tempo final (T2).

Os resultados da Figura 3 confirmam o efeito de diminuição de TOC com o tempo. Para o IC, tem-se também uma diminuição brusca em ambas as amostras, indicando que o processo já não é mais tão eficaz.

As Figuras 4, 5 e 6 trazem os resultados obtidos para as amostras de água produzida.

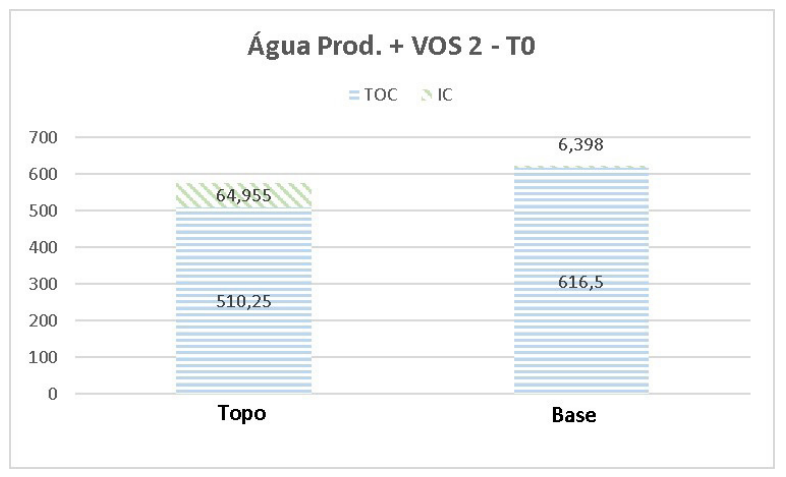

Figura 4. Comparação de TOC e IC entre topo e base de amostra de água produzida em tempo inicial (T0). 
Pela figura 4, é possível perceber o alto nível de carbono orgânico inicialmente na amostra, sendo os primeiros momentos do processo os mais cruciais para o resultado final da separação.

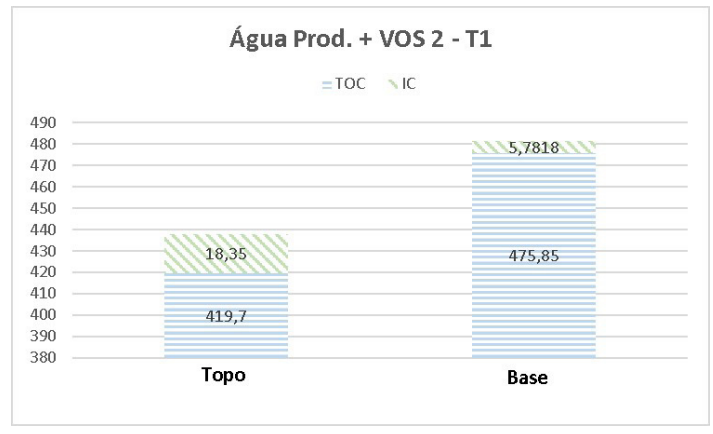

Figura 5. Comparação de TOC e IC entre topo e base de amostra de água produzida em tempo intermediário (T1).

Ao comparar o tempo inicial na figura 4, e o tempo intermediário de coleta na figura 5 , destaca-se o decrescimento do TOC em ambos os campos de coleta na coluna.

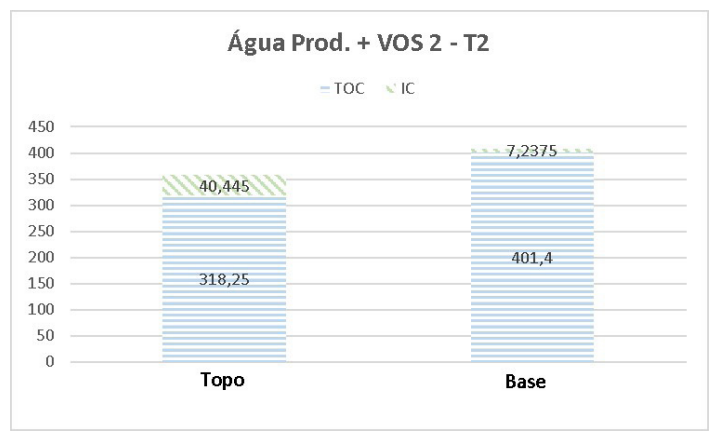

Figura 6. Comparação de TOC e IC entre topo e base de amostra de água produzida em tempo final (T2).

A partir da figura 6, percebe-se que esse comportamento de decrescimento continua. Dessa forma, deve-se encontrar um outro tempo de residência da amostra na coluna, provavelmente menor que o utilizado, obtendo melhores resultados para TOC.

\section{Conclusões}

O processo de flotação por ar induzido mostra-se promissor para tempos de residência curtos. Os melhores resultados obtidos se repetem quando a amostra é retirada no início do processo (T0), sendo este comportamento evidenciado para ambos os efluentes. Destaca-se um melhor desempenho na remoção de carbono orgânico para a água industrial, já a água produzida carece de alternativas que potencializem o processo.

\section{Agradecimentos}

Ao Núcleo de Ensino e Pesquisa em Petróleo e Gás da Universidade Federal do Rio Grande do Norte pela infraestrutura cedida para realização dos experimentos. À Universidade de São Paulo que disponibilizou sua infraestrutura do prédio Semi-Industrial para realização de parte dos experimentos. E à Capes e ao Programa Nacional de Cooperação Acadêmica (PROCAD) pelo apoio financeiro.

\section{Referências Bibliográficas}

1. NEFF, J. M., Bioaccumulation in marine organisms Effect of contaminants from oil well produced water. Ed. Elsevier Science Ltd.: Amsterdam, pp. 1-34, 2002.

2. Rubio, J.; SOUZA, M. L.; SMITH, R.W. Overview of flotation as a wastewater treatment technique. Minerals Engineering, v.15, p.139155,2002

3. Yoon, R. H., The role of hydrodynamic and surface forces in bubble-particle interaction, International Journal of Mineral Processing. v.58, 129-143, 2000.

\section{Beatriz I. O. Vieira, Dannielle J. Silva, Hermano G. Fernandes \& Osvaldo Chiavone-Filho*}

Departamento de Engenharia Química, NUPEG/FOTEQ, Universidade Federal do Rio Grande do Norte, Natal, RN, Brasil.

*E-mail: osvaldo@eq.ufrn.br 